\title{
The Efficacy and Safety of Postoperative Autologous Transfusion of Filtered Shed Blood and Anticoagulant Prophylaxis in Total Knee Arthroplasty Patients
}

\author{
Kwon-Hee Park, MD, Sung-Rak Lee, MD, Jong-Mun Jin, MD and Myung-Sang Moon, MD
}

Department of Orthopaedic Surgery, Cheju Halla General Hospital, Jeju, Korea

\begin{abstract}
Purpose: To assess the efficacy and safety of autologous transfusion of filtered shed blood in total knee arthroplasty (TKA).
Materials and Methods: A total of 42 patients with TKA (group A; without autologous transfusion in 15 patients, group B; with autologous transfusion in 27 patients) were evaluated retrospectively. The influence of autologous reinfusion of filtered blood, bleeding tendency, amount of blood drainage, rate of allogenic transfusion, and the postoperative changes of hemoglobin were analyzed.

Results: Allogenic transfusion was needed in 26.7\% (4/15) of group A and none of group B till postoperative 48 hours. Till postoperative 14 days, $46.7 \%(7 / 15)$ of group A needed allogenic transfusion while $7.4 \%(2 / 27)$ in group B. The average drained blood volume was $1,197 \pm 400 \mathrm{~mL}$ in group $\mathrm{A}$ and $975 \pm 422 \mathrm{~mL}$ in group $\mathrm{B}$. The average decrease of hemoglobin at postoperative 1,7 , and 14 days was $2.9 \pm 1.5,2.9 \pm 1.6$, and $2.3 \pm 1.5 \mathrm{~g} / \mathrm{dL}$ respectively in group A and $2.7 \pm 0.8,4.0 \pm 1.0$, and $2.9 \pm 1.3 \mathrm{~g} / \mathrm{dL}$ respectively in group $\mathrm{B}$.

Conclusions: An autotransfusion system lowered the allogenic transfusion rate, while anticoagulants did not increase the amount of drained blood. An autotransfusion system with anticoagulants was effective and safe to save the shed blood in TKA.
\end{abstract}

Key words: Total knee arthroplasty, Autotransfusion, Anticoagulants.

\section{Introduction}

Suction drainage in total knee arthroplasty (TKA) has been used primarily to prevent hemoarthrosis, hematomas and infections, and secondly to promote wound healing and rehabilitation ${ }^{1)}$. In general, a large amount of blood is lost during and after surgery, which requires allogenic transfusion to stabilize the patient's vital signs. To reduce the amount of allogenic transfusion, various autotransfusion systems have been introduced. TKA-associated

Received June 13, 2011; Revised (1st) July 4, 2011;

(2nd) September 7, 2011; Accepted October 4, 2011.

Correspondence to: Sung-Rak Lee, MD.

Department of Orthopaedic Surgery, Cheju Halla General Hospital, 65 Doryeong-ro, Jeju 690-170, Korea.

Tel: +82-64-740-5030, Fax: +82-64-743-3110

Email: drthatka@yahoo.co.kr

This is an Open Access article distributed under the terms of the Creative Commons Attribution Non-Commercial License (http://creativecommons.org/licenses/by-nc/3.0/) which permits unrestricted non-commercial use, distribution, and reproduction in any medium, provided the original work is properly cited. deep vein thrombosis (DVT) can cause fatal pulmonary embolism $(\mathrm{PE})^{2)}$ and prophylactic anticoagulants have been commonly used to prevent DVT. In this study, we assessed the efficacy of autologous transfusion of filtered shed blood on bleeding tendency and vital signs and safety of anticoagulation prophylaxis.

\section{Materials and Methods}

\section{Materials}

Between January 2006 and May 2010, 42 female patients with unilateral TKA by a single surgeon were enrolled in the present study. Patients with a history of bleeding tendency were excluded. Fifteen TKA patients (group A) had a suction drain (Baro-Vac, Sewoon Medical, Cheonan, Korea) only without anticoagulant, while 27 TKA patients (group B) received autotransfusion (Consta-Vac, Stryker, Michigan, MI, USA) and anticoagulant therapy using Fondaparinux (Arixtra, Glaxo Smith Kline, London, England). The maximum negative pressure of Baro-Vac was $90 \mathrm{~mm} \mathrm{Hg}$ and we used half pressure. The negative pressure of Consta-Vac was $50 \mathrm{~mm} \mathrm{Hg}$.

The mean age of group A and B patients was 72.9 (range, 54 
to 82 ) and 71.0 (range, 58 to 82 ) years, respectively. The average body mass index (BMI) was $26.5 \%( \pm 3.2)$ in group A and $24.6 \%( \pm 3.0)$ in group B. The indication for TKA was primary osteoarthritis in all patients. The demographic data of the two groups were not significantly different (Table 1).

\section{Operative Technique and Implants}

Regional anesthesia (spinal, epidural or spinal-epidural combined) was performed in all patients. In group A, 7 spinal, 6 epidural and 2 spinal-epidural anesthesia types were used. In group B, 12 spinal, 10 epidural and 5 spinal-epidural anesthesia types were used. A unilateral, posterior substitute (PS) type cemented TKA using a medial parapatellar incision was performed. Patellar resurfacing was done and a pneumatic tourniquet was used during surgery in all patients. After tourniquet release, meticulous hemostasis was performed. The shed blood during this bleeding control period was discarded. Because the same operative procedure was performed in group $A$ and $B$, we thought there were no significant differences in the discarded blood. Therefore, the blood lost during surgery was not measured and not included in this study.

In group A, 8 genesis II (Smith \& Nephew, Memphis, TN, USA) and 7 Scorpio (Osteonics, NJ, USA) were used, and in group B, 11 Genesis II and 16 Scorpio were used.

\section{Postoperative Management}

Drainage was discontinued at 48 hours postoperatively in both groups because of a potential increase in the bacterial colonization rate if left longer. Group B patients received autotransfusion of the drained filtered blood that was collected during the first 6 postoperative hours, and the subcutaneous anticoagulant (Fondaparinux $2.5 \mathrm{mg}$ per day: Arixtra) therapy was started at 6 hours postoperatively until postoperative day 7. In both groups, allogenic transfusion was indicated when the hemoglobin concentration was $<7 \mathrm{~g} / \mathrm{dL}$ or when vital signs were unstable or the hemoglobin concentration was $<9 \mathrm{~g} / \mathrm{dL}$ and acute hypovolemic symptoms developed such as hypotension below $100 \mathrm{~mm} \mathrm{Hg}$ of systolic blood pressure, tachycardia above 100/ min, decreased urine output below $20 \mathrm{~mL} / \mathrm{h}$, and dizziness ${ }^{3,4)}$.

To evaluate the clinical validity of autologous transfusion of

Table 1. Demographic Data of the Patients in This Study

\begin{tabular}{lcc}
\hline & Group A & Group B \\
\hline No. of patients & 15 & 27 \\
Mean age & $72.9(54-82)$ & $71.0(58-82)$ \\
Body mass index $(\%)$ & $26.5 \pm 3.2$ & $24.6 \pm 3.0$ \\
\hline
\end{tabular}

the filtered shed blood, the frequency of allogenic transfusion was analyzed until the postoperative day 14 , and the changes in hemoglobin were analyzed statistically at postoperative 24 hours, day 7 and day 14 . To evaluate the effect of anticoagulant prophylaxis on bleeding tendency, the amount of drained blood was analyzed till 48 hours postoperatively. The symptoms of thrombophlebitis were also checked till the 14th postoperative day. The percentage of patients needing an allogenic transfusion in each group was determined. Statistical analysis was performed using chi-square analysis for categorical data. The amount of drained blood and reduction in hemoglobin according to the usage of anticoagulants were compared statistically by conducting the Student's $t$-test. All statistical analyses were performed with an IBM SPSS statics ver. 19 (IBM Corporation, Somers, NY, USA). A p-value $<0.05$ was considered statistically significant.

\section{Results}

\section{The Frequency of Allogenic Transfusion}

Allogenic transfusion was needed in $26.7 \%$ (4/15) of patients in group A and none in group B until 48 hours postoperatively. Until postoperative day 14, transfusion was needed in $46.7 \%$ (7/15) of patients in group A and 7.4\% (2/27) in group B. Statistically, the autotransfusion system reduced allogenic transfusion rates $(\mathrm{p}<0.05)$ (Table 2$)$.

\section{Autologous Tranfusion and Autotransfusion System- \\ Related Complications}

The average amount of autotransfusion was $490 \mathrm{~mL}( \pm 202)$. No complications (febrile reaction, bacterial infection, fat embolism,

Table 2. The Rate of Allogenic Transfusion, Amount of Drained Blood and Change of Hemoglobin

\begin{tabular}{|c|c|c|c|}
\hline & $\begin{array}{c}\text { Group A } \\
(\mathrm{n}=15)\end{array}$ & $\begin{array}{c}\text { Group B } \\
(\mathrm{n}=27)\end{array}$ & p-value \\
\hline $\begin{array}{l}\text { Allogenic transfusion (till POD } \\
\text { 2nd day) }\end{array}$ & $4 / 15(26.7)$ & $0 / 27(0)$ & 0 \\
\hline $\begin{array}{l}\text { Allogenic transfusion (till POD } \\
\text { 14th day) }\end{array}$ & $7 / 15(46.7)$ & $2 / 27(7.4)$ & 0.005 \\
\hline $\begin{array}{l}\text { Amount of drain (till } \\
\text { postoperative } 48 \mathrm{hr} \text { ) }\end{array}$ & $1,197 \pm 400$ & $975 \pm 422$ & 0.104 \\
\hline Preoperative hemoglobin $(\mathrm{g} / \mathrm{dL})$ & $12.0 \pm 1.1$ & $12.4 \pm 0.9$ & 0.219 \\
\hline Change of $\mathrm{Hb}(\mathrm{POD} 1, \mathrm{~g} / \mathrm{dL})$ & $2.9 \pm 1.5$ & $2.7 \pm 0.8$ & 0.564 \\
\hline Change of $\mathrm{Hb}(\mathrm{POD} 7, \mathrm{~g} / \mathrm{dL})$ & $2.9 \pm 1.6$ & $4.0 \pm 1.0$ & 0.021 \\
\hline Change of $\mathrm{Hb}$ (POD 14, g/dL) & $2.3 \pm 1.5$ & $2.9 \pm 1.3$ & 0.221 \\
\hline
\end{tabular}


coagulopathy, itching and urticaria, etc.) related to autologous transfusion of the filtered shed blood were noted clinically.

\section{The Amount of Drained Blood}

The average amount of drained blood was 1,197 mL $( \pm 400)$ in group A and $975 \mathrm{~mL}( \pm 422)$ in group B until 48 hours postoperatively. The use of an anticoagulant (Fondaparinux: Arixtra) did not result in significant increases in the amount of drained blood ( $p>0.05$ ) (Table 2).

\section{The Average Hemoglobin Level}

The average preoperative hemoglobin level was $12.0( \pm 1.1)$ in group A and $12.4( \pm 0.9)$ in group B. The postoperative hemoglobin level was measured at postoperative days 2, 7 and 14. The average decrease in the hemoglobin level at 24 hours postoperatively and at postoperative days 7 and 14 was $2.9 \mathrm{~g} /$ $\mathrm{dL}( \pm 1.5), 2.9 \mathrm{~g} / \mathrm{dL}( \pm 1.6)$ and $2.3 \mathrm{~g} / \mathrm{dL}( \pm 1.5)$, respectively, in group A and $2.7 \mathrm{~g} / \mathrm{dL}( \pm 0.8), 4.0 \mathrm{~g} / \mathrm{dL}( \pm 1.0)$ and $2.9 \mathrm{~g} /$ dL $( \pm 1.3)$, respectively, in group B. A statistically significant intergroup difference was found in the value obtained at 24 hours postoperatively $(\mathrm{p}<0.05)$, not at postoperative days 7 and 14 $(\mathrm{p}>0.05)$ (Table 2).

\section{Complications Related to Prophylactic Anticoagulant Therapy}

No specific complication was noted postoperatively in group A and B. To diagnosis DVT, we checked clinical symptoms such as pain, edema, tenderness, body temperature, heart rate and Homan's sign, and related symptoms were not noted in both groups. Particularly in group B with anticoagulant therapy, no complications such as bleeding, hematoma or wound problems developed until postoperative day 14 . We did not find any surgical site complications that correlated with BMI either. The anesthesiologist did not consider the regional anesthesia method using anticoagulants. The epidural catheters were removed by 48 hours postoperatively in all patients and no complication such as epidural hematoma developed.

\section{Discussion}

\section{The Effect and Safety of Autologous Transfusion of Filtered Shed Blood}

Blood loss after TKA has been known to be about 500-1,500 $\mathrm{mL}$. It has been known that the amount of blood loss affects the prognosis of $\mathrm{TKA}^{5)}$. Therefore, various autotransfusion systems have been used to reduce the side effects of allogenic transfusion and to save shed blood. In some studies, autologous transfusion of filtered shed blood resulted in complications such as febrile reaction, hypotension, bacterial infection, fat embolism, coagulopathy, itching and urticaria ${ }^{6-8)}$. However, these side effects have been rarely reported. In addition, the safety of filtered shed autotransfusion has been documented in various studies ${ }^{9-14)}$. In our study, no complications related to autologous transfusion were noted in the clinical assessment.

Allogenic transfusion was needed in $26.7 \%$ (4/15) of patients in group A and none in group B until 48 hours postoperatively. Until postoperative day 14, the transfusion was needed in $46.7 \%$ (7/15) of patients in group A and 7.4\% (2/27) in group B. The autotransfusion system (Consta-Vac) was effective in lowering the incidence of allogenic transfusion at a significant level $(\mathrm{p}<0.001)$.

\section{The Effect and Safety of Anticoagulant}

The use of prophylactic anticoagulant is important because the incidence of DVT after TKA is higher than other surgeries and DVT can cause fatal PE. Stulberg et al. ${ }^{15)}$ reported about $84 \%$ deep-vein thrombosis following total knee replacement without anticoagulant prophylaxis. Cha et al. ${ }^{16)}$ reported that venous thromboembolism occurred in $40.4 \%$ of cases following total knee replacement without anticoagulant prophylaxis and that TKA was a risk factor for DVT and PE. Some studies reported that the incidence of DVT in Asians was low ${ }^{17,18)}$, but recent epidemiological studies disclosed that the incidence of DVT in Asians has been increasing ${ }^{19,20)}$. Brookenthal et al..$^{2)}$ reported the overall incidence of fatal PE was $0.22 \%$ and Howie et al. ${ }^{21)}$ and SooHoo et al ${ }^{22)}$ reported $0.15 \%$ and $0.41 \%$ of fatal PE within 90 days after TKA. The use of prophylactic anticoagulant is very important because of the high mortality of symptomatic $\mathrm{PE}^{23)}$.

To prevent DVT, standard pneumatic compression, inferior vena cava filter and pharmacologic prophylaxis can be used. The existing pharmacologic options are parenteral heparin, oral warfarin (inhibitor of vitamin K), low-molecular-weight heparin (Dalteparin, Enoxaparin, Lovenox), Fondaparinux (inhibitor of factor Xa) and inhibitor of platelet aggregation (Aspirin, Naproxen, NSAIDs). An oral form of heparin (Melagtran, Ximelagatran, Dabigatran, Rivaroxaban, Apixaban) as well as direct thrombin inhibitors of factors IIa, IXa and Xa are being developed ${ }^{24-26)}$. Fondaparinux sodium (Arixtra $2.5 \mathrm{mg} / 0.5$ $\mathrm{mL}$ ) is the first synthetic inhibitor of factor Xa and has a single molecular target within the coagulation cascade. In the current series, it was administered subcutaneously from 6 hours after surgery until 5-9 days following surgery (2.5 mg once daily $)^{27)}$. 
The anticoagulant-related complications include bleeding, hematoma and wound problem ${ }^{5,28)}$. However, Turpie ${ }^{27)}$ presented rare side effects of fondaparinux including bleeding until postoperative day 11 . To evaluate the effect and safety of anticoagulants on bleeding tendency, blood analysis has to be done but unfortunately it is an expensive procedure. Bleeding is the most concerning side effect of anticoagulant therapy. Therefore, we simply evaluated the amount of drained blood. It is simple and economical, and has high clinical validity. We believe the amount of drained blood reflects bleeding tendency clinically. In most cases, bleeding stopped within 2-3 postoperative days, and consequently the drainage was also removed ${ }^{1,6,9,10,29)}$. The average amount of drained blood until 48 hours after surgery was $1,197 \mathrm{~mL}( \pm 400)$ in group A and $975 \mathrm{~mL}( \pm 422)$ in group B. Anticoagulant therapy did not significantly increase the amount of drained blood ( $p>0.05$ ). High incidence of DVT can cause fatal PE secondarily. Therefore, a prophylactic anticoagulant is recommended. As a result, non DVT was complicated in the current series.

\section{The Limitation of This Study}

Limitations of this study include the lack of providing the amount of blood loss during wound closure after tourniquet release, planned blood analysis (bleeding time, coagulation time and prothrombin time) and accurate diagnosis of DVT postoperatively. The assumptive asymptomatic complications such as hemoarthrosis and asymptomatic DVT have to be evaluated prospectively.

We expected that the average hemoglobin level would not be different between group A and B, but there were statistically significant differences at postoperative day 7 . We hypothesized that this was attributable to either allogenic transfusion or the anticoagulant. In group A, allogenic transfusion was needed in $46.7 \%$ (7/15) of patients until postoperative day 7. In group $\mathrm{B}$, allogenic transfusion was needed in $7.4 \%(2 / 27)$ of patients due to anemia at 7 days postoperatively and gastroduodenal ulcer at 10 days postoperatively. High frequency of allogenic transfusion in group A would have affected the hemoglobin level at 7 days postoperatively. Also, the hemodynamic effect of anticoagulants has the potential of lowering the hemoglobin at 7 days postoperatively. Further evaluation is needed fully clarify this issue.

\section{Conclusions}

An autotransfusion system (Consta-Vac) reduced the allogenic transfusion rates. Anticoagulants (Fondaparinux: Arixtra) did not increase the amount of drained blood. Autotransfusion system with anticoagulant was effective and safe to save shed blood and prevent thrombophlebitis and thromboembolism after TKA.

\section{References}

1. Song MH, Kim BH, Kim TK. Is suction drainage necessary after total knee arthroplasty? J Korean Orthop Assoc. 2004;39:186-91.

2. Brookenthal KR, Freedman KB, Lotke PA, Fitzgerald RH, Lonner JH. A meta-analysis of thromboembolic prophylaxis in total knee arthroplasty. J Arthroplasty. 2001;16:293-300.

3. Murphy MF, Wallington TB, Kelsey P, Boulton F, Bruce M, Cohen H, Duguid J, Knowles SM, Poole G, Williamson LM; British Committee for Standards in Haematology, Blood Transfusion Task Force. Guidelines for the clinical use of red cell transfusions. Br J Haematol. 2001;113:24-31.

4. Mallett SV, Peachey TD, Sanehi O, Hazlehurst G, Mehta A. Reducing red blood cell transfusion in elective surgical patients: the role of audit and practice guidelines. Anaesthesia. 2000;55:1013-9.

5. Bauer KA, Eriksson BI, Lassen MR, Turpie AG; Steering Committee of the Pentasaccharide in Major Knee Surgery Study. Fondaparinux compared with enoxaparin for the prevention of venous thromboembolism after elective major knee surgery. N Engl J Med. 2001;345:1305-10.

6. Han CD, Shin DE. Postoperative blood salvage and reinfusion after total joint arthroplasty. J Arthroplasty. 1997;12:511-6.

7. Handel M, Winkler J, Hornlein RF, Northoff H, Heeg P, Teschner M, Sell S. Increased interleukin-6 in collected drainage blood after total knee arthroplasty: an association with febrile reactions during retransfusion. Acta Orthop Scand. 2001;72:270-2.

8. Lemos MJ, Healy WL. Blood transfusion in orthopaedic operations. J Bone Joint Surg Am. 1996;78:1260-70.

9. Bae DK, Nam GU, Lee HK, Kim YH. Reinfusion of shed blood through the orth-evac after total knee replacement. J Korean Orthop Assoc. 1994;6:88-93.

10. Bae DK, Park BY, Kim YH, Kwon OS. Autotransfusion of the autologous shed blood after total knee replacement. J Korean Orthop Assoc. 1995;30:651-7.

11. Chimutengwende-Gordon M, Khan WS, Maruthainar N. Perioperative blood transfusion: the role of allogenous and autologous transfusions, and pharmacological agents. J 
Perioper Pract. 2010;20:283-7.

12. Dalen T, Nilsson KG, Engstrom KG. Fever and autologous blood retransfusion after total knee arthroplasty: a prospective study of 40 autotransfusion events in 21 patients. Acta Orthop Scand. 2002;73:321-5.

13. Munoz Gomez M, Garcia Vallejo J, Lopez-Andrade Jurado A, Gomez Luque A, Ruiz Romero De La Cruz M, Maldonado Eloy-Garcia J. Autotransfusion after orthopedic surgery. Analysis of quality, safety and efficacy of salvaged shed blood. Rev Esp Anestesiol Reanim. 2001;48:131-40.

14. Sebastian C, Romero R, Olalla E, Ferrer C, Garcia-Vallejo JJ, Munoz M. Postoperative blood salvage and reinfusion in spinal surgery: blood quality, effectiveness and impact on patient blood parameters. Eur Spine J. 2000;9:458-65.

15. Stulberg BN, Insall JN, Williams GW, Ghelman B. Deep-vein thrombosis following total knee replacement. An analysis of six hundred and thirty-eight arthroplasties. J Bone Joint Surg Am. 1984;66:194-201.

16. Cha SI, Lee SY, Kim CH, Park JY, Jung TH, Yi JH, Lee J, Huh S, Lee HJ, Kim SY. Venous thromboembolism in Korean patients undergoing major orthopedic surgery: a prospective observational study using computed tomographic (CT) pulmonary angiography and Indirect CT venography. J Korean Med Sci. 2010;25:28-34.

17. Geerts WH, Pineo GF, Heit JA, Bergqvist D, Lassen MR, Colwell CW, Ray JG. Prevention of venous thromboembolism: the Seventh ACCP Conference on Antithrombotic and Thrombolytic Therapy. Chest. 2004;126:338S-400S.

18. Kim YH, Suh JS. Low incidence of deep-vein thrombosis after cementless total hip replacement. J Bone Joint Surg Am. 1988;70:878-82.

19. Leizorovicz A. Epidemiology of post-operative venous thromboembolism in Asian patients. Results of the SMART venography study. Haematologica. 2007;92:1194-200.

20. Piovella F, Wang CJ, Lu H, Lee K, Lee LH, Lee WC, Turpie AG, Gallus AS, Planes A, Passera R, Rouillon A. Deep-vein thrombosis rates after major orthopedic surgery in Asia. An epidemiological study based on postoperative screening with centrally adjudicated bilateral venography. J Thromb Haemost. 2005;3:2664-70.

21. Howie C, Hughes H, Watts AC. Venous thromboembolism associated with hip and knee replacement over a ten-year period: a population-based study. J Bone Joint Surg Br. 2005;87:1675-80.

22. SooHoo NF, Lieberman JR, Ko CY, Zingmond DS. Factors predicting complication rates following total knee replacement. J Bone Joint Surg Am. 2006;88:480-5.

23. Kim KY, Cho WS, Lee SH, Cho YS, Moon DH, Ko YS. Study on the incidence of pulmonary embolism before and after hip and knee replacement arthroplasties. J Korean Orthop Assoc. 1994;29:816-24.

24. Liu LT, Ma BT. Prophylaxis against venous thromboembolism in orthopedic surgery. Chin J Traumatol. 2006;9:24956.

25. Haas SB, Barrack RL, Westrich G. Venous thromboembolic disease after total hip and knee arthroplasty. Instr Course Lect. 2009;58:781-93.

26. Venet C, Berger C, Tardy B, Viallon A, Decousus H, Bertrand JC. Prevention of venous thromboembolism in polytraumatized patients. Epidemiology and importance. Presse Med. 2000;29:68-75.

27. Turpie AG. Venous thromboembolism prophylaxis: role of factor xa inhibition by fondaparinux. Surg Technol Int. 2004;13:261-7.

28. Lachiewicz PF. Prevention of symptomatic pulmonary embolism in patients undergoing total hip and knee arthroplasty: clinical guideline of the American Academy of Orthopaedic Surgeons. Instr Course Lect. 2009;58:795-804.

29. Sung JH, Kim WY, Han CW, Cha WJ, Kim JY. Necessity of banked autogenous transfusion on the total knee arthroplasty using autogenous shed blood transfusion. J Korean Orthop Assoc. 1998;33:702-6. 